\title{
The Paleobiosphere: a novel device for the in vivo testing of hydrocarbon production utilizing microorganisms
}

\author{
Authors: Gary Strobel, Eric Booth, George Schaible, \\ Morgan Tess Mends, Joe Sears, and Brad Geary
}

NOTICE: this is the author's version of a work that was accepted for publication in Biotechnology Letters. Changes resulting from the publishing process, such as peer review, editing, corrections, structural formatting, and other quality control mechanisms may not be reflected in this document. Changes may have been made to this work since it was submitted for publication. A definitive version was subsequently published in Biotechnology Letters, [VOL\# 35, ISSUE\# 4, (2013)] DOI\# 10.1007/s10529-012-1123-0

Strobel, G.A. Booth, E., Schaible, G., Mends, M.T., Sears, J.,Geary, B., (2013). The Paleobiosphere: a novel device for the in vivo testing of hydrocarbon production -utilizing microorganisms. Biotechnology Letters 35 (4): 539-552.

http://dx.doi.org/10.1007/s10529-012-1123-0

Made available through Montana State University's ScholarWorks scholarworks.montana.edu 


\title{
The Paleobiosphere: a novel device for the in vivo testing of hydrocarbon production utilizing microorganisms
}

\author{
Gary Strobel • Eric Booth $\cdot$ George Schaible • \\ Morgan Tess Mends · Joe Sears · Brad Geary
}

Received: 5 November 2012/ Accepted: 7 December 2012

(C) Springer Science+Business Media Dordrecht 2012

\begin{abstract}
The construction and testing of a unique instrument, the Paleobiosphere, which mimics some of the conditions of the ancient earth, is described. The instrument provides an experimental testing system for determining if certain microbes, when provided an adequate environment, can degrade biological materials to produce fuel-like hydrocarbons in a relatively short time frame that become trapped by the shale. The conditions selected for testing included a particulate Montana shale (serving as the "Trap Shale"), plant materials (leaves and stems of three extant species whose origins are in the late Cretaceous), a watercirculating system, sterile air, and a specially designed Carbotrap through which all air was passed as exhaust and volatile were hydrocarbons trapped. The fungus for initial testing was Annulohypoxylon sp., isolated as an endophyte of Citrus aurantifolia. It produces, in solid and liquid media, a series of hydrocarbon-like molecules. Some of these including 1,8-cineole, 2-butanone, propanoic acid, 2-methyl-, methyl ester, benzene
\end{abstract}

G. Strobel (\&) · E. Booth · G. Schaible · M. T. Mends

Department of Plant Sciences, Montana State University,

Bozeman, MT 59717, USA

e-mail: uplgs@montana.edu

J. Sears

Center for Lab Services/RJ Lee Group,

2710 North 20th Ave., Pasco, WA 99301, USA

B. Geary

Department of Plant and Wildlife Sciences,

Brigham Young University, Provo, UT 84602, USA (1-methylethyl)-, phenylethyl alcohol, benzophenone and azulene, 1,2,3,5,6,7,8,8a-octahydro-1,4-dimethyl7-(1-methylethenyl), [1S-(1a,7a,8ab)]. These were the key signature compounds used in an initial Paleobiosphere test. After 3 weeks, incubation, the volatiles associated with the harvested "Trap Shale" included each of the signature substances as well as other fungalassociated products: some indanes, benzene derivatives, some cyclohexanes, 3-octanone, naphthalenes and others. The fungus thus produced a series of "Trap Shale" products that were representative of each of the major classes of hydrocarbons in diesel fuel (Mycodiesel). Initial tests with the Paleobiosphere offer some evidence for a possible origin of hydrocarbons trapped in bentonite shale. Thus, with modifications, numerous other tests can also be designed for utilization in the Paleobiosphere.

Keywords Carbotraps - Bentonite shale · Cyclohexanes · Mycodiesel · Cineole . Endophytic fungi

\section{Introduction}

In the recent past many endophytic fungi have been isolated from trees associated with temperate and tropical rainforests (Strobel and Daisy 2003). Some of these organisms emit hydrocarbons and hydrocarbon derivatives that have fuel potential, named as Mycodiesel (Ahamed and Ahring 2011; Banerjee et al. 2010; 
Gianoulis et al. 2012; Griffin et al. 2010; Hassan et al. 2012; Mallette et al. 2012; Mends et al. 2012; Strobel et al. 2008; Tomsheck et al. 2010). These endophytes, by definition, live in association with their host plants and produce no apparent evidence of their presence in them (Bacon and White 2000). Thus, as their host plant matures and falls to the forest floor the endophytes are the first to initiate the multitudinous processes associated with decay and nutrient recycling (Ahamed and Ahring 2011; Strobel et al. 2008). The hypothesis that some of these endophytic organisms may have been, in part, responsible for the production of ancient shalebased hydrocarbons (crude oil) has been proposed since it is composed of some of the same classes of hydrocarbons as made by these contemporary endophytic fungi (Booth et al. 2011; Hassan et al. 2012; Strobel et al. 2008; Tomsheck et al. 2010). For instance, diesel fuel is a condensation product of heated crude oil. Essentially, it contains only 4 major classes of organic compounds consisting of straight and branched chained hydrocarbons, cyclic alkanes, benzene derivatives and polyaromatic hydrocarbons such as the naphthalenes (Song et al. 2000). Specific endophytes are now known that make one or more of the representative compounds in each of these classes of diesel hydrocarbons (Booth et al. 2011; Gianoulis et al. 2012; Hassan et al. 2012; Strobel et al. 2008; Tomsheck et al. 2010).

Recently, evidence has emerged for the presence of wood and leaf-associated petrified fungi in oil-rich Montana shales and additional information on this matter is presented in this report. Collectively, these data provide the basis for a reasonable and testable hypothesis that fungi may have contributed to the formation of some of the shale-related volatiles by virtue of their ability to degrade plant materials into hydrocarbons that were ultimately trapped and retained by the unique physical framework of shales and related materials.

The rationale for this report is based on the premise that a properly planned and executed experimental test system may effectively produce and trap fungal-based hydrocarbons in shale using plant materials as a substrate and an appropriate fungus to degrade these materials. The design of the system is based on the presumed conditions that mainly existed during the Cretaceous period, when the earth very much resembled the present day areas of SE United States from Florida to the Mississippi delta region, and when the deposition of hydrocarbons seems to have occurred (Finn et al. 2010; Heck et al. 2012). As an example, the area, of what is now Eastern Montana and Western North Dakota, when not under water, was part of a hot humid coastline of rivers, and river deltas bearing dense vegetation that bordered the ancient shallow inland sea. This sea covered an area from the present day Gulf of Mexico to Hudson's Bay and included massive shale deposits that underlay and were otherwise associated with the sea.

In order to test the hypothesis that fungi associated with plants may have produced hydrocarbons that were trapped by what are now ancient shale deposits, a device dubbed a "Paleobiosphere", has been designed. It includes a chamber with the appropriate materials to produce hydrocarbon rich shale by degradation of appropriate extant plant species using an endophytic fungus that produces hydrocarbons. Its design also permits water in varying amounts, filtered sterile air and a Carbotrap to collect all hydrocarbons being produced by the system while not being collected by the shale. Such an instrument has been built and subjected to testing with all of the necessary ingredients. A description of it and results from experimental tests conducted with it are presented in this report.

\section{Materials and methods}

\section{The Paleobiosphere (PBS)}

The instrument has been constructed from stainless steel parts including the main chamber and all valves, ports and traps. Tygon tubing lined with Teflon provides for all tube connections. The main chamber is $30 \mathrm{~cm}$ long, $21.5 \mathrm{~cm}$ wide and $14 \mathrm{~cm}$ deep (Fig. 1). The chamber has a sealed viewing port assembled on the top side. It also has a port connection to a water reservoir containing 21 of sterile water with access to outside air via a stainless steel tube having a PALL $0.2 \mathrm{~lm}$ PTFE air filter mounted on it to equalize the pressure with sterile air (Fig. 1). The chamber also has an inlet valve allowing for the entry of air that has been passed through an air purifier (charcoal) as well as an air sterilization filter (as above). At the base of the main chamber is another port with a three-way valve connected to a peristaltic pump via the chamber and an exit port on the right side allowing for water circulation through the pump and alternatively as an exhaust to the waste water trap. This easily allows for water to be replaced during the initial leaching processes. 


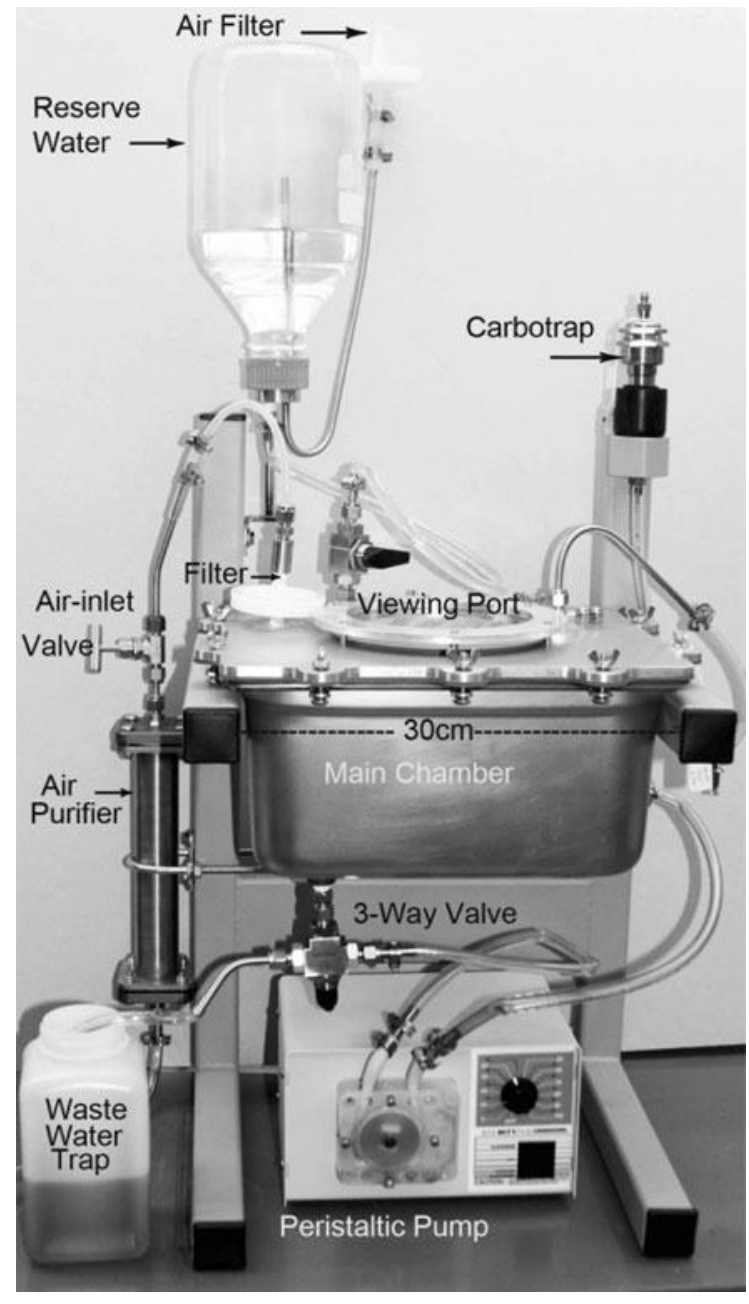

Fig. 1 The Paleobiosphere as designed and built and used in the experiments outlined in this report. Details on each component and how it was employed are found in the text

Mounted on the top right side is a patented stainless steel column containing $10 \mathrm{~g}$ each (in line with each other) of Carbotrap materials A and B (Supelco Co.; Booth et al. 2011). The entire system has been built air-tight with the only air access being the air inlet system on the left side of the chamber (Fig. 1). A viewing port allows for monitoring of the events transpiring within the chamber.

\section{Materials for the PBS}

\section{Plant specimens}

Leaves of plant species that are extant but whose relatives were contemporary during the late-Cretaceous period were chosen for this study since they are available (Tidwell 1998). They served as the nutritive base for the fungus that was added to the PBS. These plants include Acer platanoides, Platanus occidentalis (both in the family Sapindaceae) and Populus tremuloides (Salicaceae), and were collected in the Intermountain West. Their early counterparts have been found in late Cretaceous and Tertiary deposits in the Intermountain West-USA (Fig. 2; Tidwell 1998). They were cut into smaller pieces ca. 2 or 394 to $5 \mathrm{~cm}$ along with small stem fragments about 2-4 cm in length and autoclaved prior to placement in the PBS.

\section{Shale}

The selection of this material is critical to providing a testing basis for the hypothesis that shale can serve as a trap of biologically derived hydrocarbons. Normally, bentonite (shale), when water is added, behaves by quickly forming a pasty-like amorphous clay and as such would make it too difficult to handle in the experimental system. Therefore, more particulate and stable shale was needed for these experiments. It was found and collected from a roadside in the Melstone/ Mosby, Montana area at $46^{\circ} 58^{0} 39^{00} \mathrm{~N} 107^{\circ} 54^{0} 49^{00} \mathrm{~W}$ in an area of active oil production. It was pulverized and then separated with two screens at 8 and 16 mesh sizes. The material remained as particulates even when soaked in water. It was prebaked at $180{ }^{\circ} \mathrm{C}$ for 30 min under a constant stream of $\mathrm{N}_{2}$ to remove residual hydrocarbons and used as the "bed shale". The shale to be used as "Trap Shale" was the same size but it had been baked for an additional $1 \mathrm{~h}$ at $300{ }^{\circ} \mathrm{C}$ also in a flow of $\mathrm{N}_{2}$. This shale ("Trap Shale" = $200 \mathrm{~g}$ ) was evenly distributed in a 12928 $\mathrm{cm}$ stainless steel 24-mesh envelope, and then placed on top of the mixture of bed shale and plant materials for use as the hydrocarbon trap. All shales incorporated into the biosphere were autoclaved twice for at least 25 min each.

\section{Fungus}

This microorganism was obtained as an endophyte from the fruit and stems of Citrus aurantifolia (Rutaceae - an ancient plant family genetically related to Sapindaceae) in a subtropical forest of Southwestern Florida in an environment very much resembling that Cretaceous period of Eastern Montana. The fungus was 


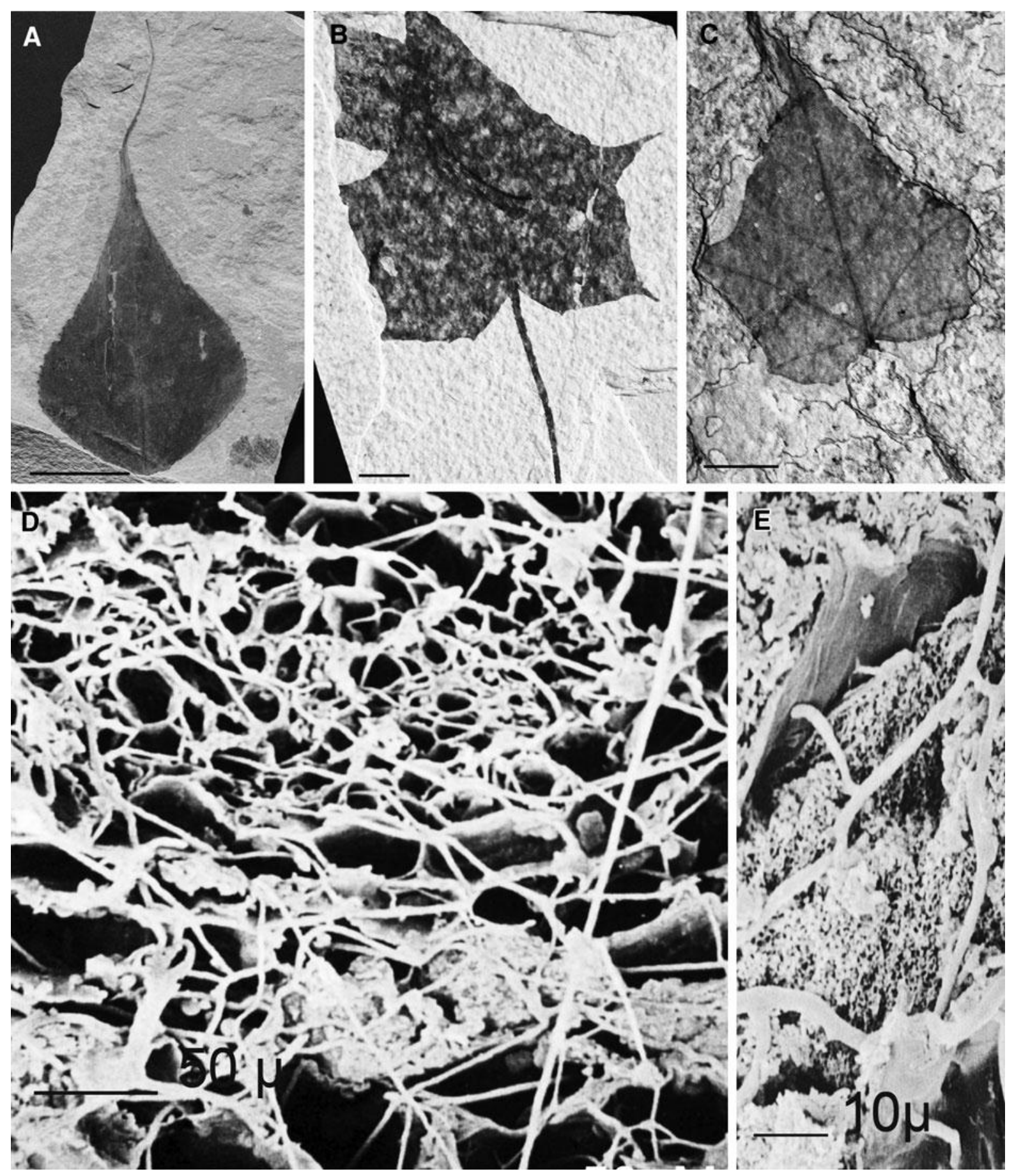

Fig. 2 Paleobotanical examples of the plants used in the PBS experiments. Illustrations $\mathrm{a}, \mathrm{b}$ and $\mathrm{c}$ represent Populus sp., Platanus sp. and Acer sp. as specimens known from late Cretaceous shales of

characterized as an Annulohypoxylon sp. on the basis of its ITS sequence identity (99\% level on ca. 831 bp) to other isolates of Annulohypoxylon stygium that the Western USA (the bars $1.5 \mathrm{~cm}$ ). Likewise, illustrations $\mathrm{c}$ and $\mathrm{d}$ represent petrified fungal hyphae penetrating petrified wood samples recovered from the oil rich Melstone, Mt. area

had been deposited in Genbank. Its exact species designation is uncertain. All of the methods for obtaining sequence data are previously outlined (Mends, 
Schaible, Strobel unpublished observations; Ezra et al. 2004; Tomsheck et al. 2010). No sexual fruiting bodies were observed when this organism was cultured on its host tissues or host tissue extracts. Spores of the imperfect stage- Nodulisporium sp. were observed, but only infrequently in potato/dextrose/agar culture and they all were in the ca. $1.592 \mathrm{~lm}$ which is in the size range of other Nodulisporium sp. (Mends et al. 2012; Tomsheck et al. 2010). This organism was selected from a wide range of other hydrocarbon-producing fungi based on its collection site, a swampland area in Florida, and the fact that it makes 1,8-cineole and a number of other volatile signature compounds as do other Hypoxylon spp. and Daldinia spp. (Mends et al. 2012; Tomsheck et al. 2010). It was deposited in the Montana State University Culture Collection as No. 2387 and the ITS sequence is deposited in GenBank as JX 455754.

\section{Carbotrap}

This device is shown on the top right side PBS and was constructed according to all details previously presented (Booth et al. 2011). The exhaust port gases from the chamber exit through this port and it was not connected until the beginning of day 4 of the 3 week incubation period (Fig. 1). It effectively serves as a trap for all hydrocarbons not being trapped by the "Trap Shale".

\section{Water}

All water added to the PBS over the course of the experiment had been de-ionized and sterilized by autoclaving.

\section{Air}

The air source was house air that was flowing at $1 \mathrm{l} / \mathrm{min}$ through a $4922 \mathrm{~cm}$ charcoal air filter in-line with a PALL air sterilization filter and directly into the chamber as described above.

\section{Temperature}

All experiments were carried out at $22{ }^{\circ} \mathrm{C}$.
Hydrocarbon production

by the Annulohypoxylon sp. isolate

At the outset it was critical to know which hydrocarbons were capable of being produced by the fungus that was to eventually be placed in the PBS. This was accomplished in two separate systems with subsequent GC/MS analysis of the volatiles. The organism was grown for 10 days on potato/dextrose/agar (PDA) and then analyzed for the production of volatiles as described below using a 30 min exposure time of the SPME fiber. Also, the organism was grown for 14 days in a shaking 71 potato dextrose broth $(24 \mathrm{~g} / \mathrm{l})$ under a constant flow of air with the exhaust air being passed through a Carbotrap as previously described (Booth et al. 2011). The Carbotrap technology and a larger culture medium were used in order to obtain a more comprehensive view of additional volatile compounds being produced by the fungus (Hassan et al. 2012; Mends et al. 2012). The contents of the Carbotrap were eluted, condensed and trapped as a liquid as previously described and as more completely outlined below and then subjected to GC/MS (Booth et al. 2011). In all cases, appropriate control media, without the fungus, were treated in the exact manner and compounds detected therein were subtracted from the ones supporting fungal growth.

Quantitative and qualitative analyses of trapped hydrocarbons from the PBS

Carbo-trapped hydrocarbons were measured gravimetrically using before and after collection weights of the column itself after a 30 min dry purge at $30{ }^{\circ} \mathrm{C}$ with a $50 \mathrm{ml} / \mathrm{min}$ flow of dry $\mathrm{N}_{2}$ (Booth et al. 2011). Then, the hydrocarbons were eluted in a programmable oven ranging up to $250{ }^{\circ} \mathrm{C}$ over the course of $1 \mathrm{~h}$ with dry $\mathrm{N}_{2}$ at $600 \mathrm{ml} / \mathrm{min}$ and with hydrocarbon capturing in a vial bathed in liquid $\mathrm{N}_{2}$ (Booth et al. 2011). The recovered hydrocarbons were weighed and subjected to GC/MS analysis. Hydrocarbons on the "Trap Shale" were measured and obtained in the same manner. This shale carried from $7-11 \%(\mathrm{w} / \mathrm{w})$ relative to the amount of "Trap Shale" that was desorbed. The volatiles on both the Carbotrapped and "Trap Shale" samples were determined by SPME-GC/MS analysis. The final data presented were obtained by subtracting all compounds trapped in the control "Trap Shale" from the PBS 
hosting the fungus. Molecular sieves (Aldrich 4-8 mesh) were added to the "Trap Shale" samples in order to adsorb the water therein and allow for the determination of the weight of the hydrocarbon fraction (Booth et al. 2011).

For qualitative analysis of the hydrocarbons produced in all PBS samples and Carbotrap samples, the methods used were as previously described (Hassan et al. 2012; Mends et al. 2012; Strobel et al. 2008). A pre-baked SPME fiber (Supelco) 50/30 divinylbenzene/carburen on polydimethylsiloxane on a stable flex-fiber was inserted through an opening in the septum of the $30 \mathrm{ml}$ collection vial and the vapor phase were adsorbed for $45 \mathrm{~min}$ with the shale samples and only $1 \mathrm{~min}$ with the Carbotrap samples. The vapors were injected into a GC containing a $30 \mathrm{~m} 90.25 \mathrm{~mm}$ inner diameter ZB Wax capillary column with a film thickness of $0.5 \mathrm{~lm}$. A thermal program of $30{ }^{\circ} \mathrm{C}$ for $2 \mathrm{~min}$ followed by an increase to 220 at $5{ }^{\circ} \mathrm{C} / \mathrm{min}$. Ultra-high purity $\mathrm{He}$ was used as the carrier gas and the initial column head pressure was $50 \mathrm{kPa}$. Data acquisition and data processing were performed on the Hewlett Packard CHEMSTATION software system. Initial identification of the compounds produced by the endophyte was made via library comparison using the National Institute of Standards and Technology (NIST) database, and all chemical compounds described in this report use the NIST database chemical terminology. Authenticity of several compounds, identified by GC/ MS, was reconfirmed by GC/MS of authentic standards. Standard compounds were run in a comparable manner as the fungal samples. Again, all compounds appearing either in the control "Trap Shale" or the control Carbotrap eluate were subtracted from the GC/ MS results of PBS "Trap Shale" containing the fungus. Multiple GC/MS analyses were done on the Trap Shale and Carbotrap samples with comparable results.

\section{Scanning electron microscopy}

The shale samples from the PBS ("Trap Shale"treatment and control) were fixed and slowly dehydrated in ethanol, critically dried, coated with gold, and examined with an FEI XL30 SEM Field Emission Gun at $5 \mathrm{kV}$ with high vacuum mode using an EverhartThornley detector (Ezra). A gaseous secondary electron detector was used with a spot size of 3 , at $15 \mathrm{kV}$. The temperature was $4{ }^{\circ} \mathrm{C}$ with a chamber pressure ranging from 5 to $6 \mathrm{~T}$, providing humidity up to $100 \%$ at the sample. Shale/fossil samples from the field were not dehydrated and subjected directly to gold coating and SEM observations. In this manner, as previously observed, if the fungal hyphae were contemporary, and not appropriately fixed, prior to gold coating, they would collapse under the vacuum in the SEM (Hess and Strobel, 1997 unpublished).

\section{UV-Visible measurements}

Aqueous samples from the PBS that were first diluted $1: 9 \mathrm{v} / \mathrm{v}$ (sample to water) and then scanned from 540 to $230 \mathrm{~nm}$ in a $1 \mathrm{ml}$ cuvette having a $1 \mathrm{~cm}$ light path. The results are reported as total absorbance at $260 \mathrm{~nm}$ for each sample.

\section{PBS experimental design}

All parts of the instrument were sealed in aluminum foil and autoclaved for $25 \mathrm{~min}$. The water, shale and plant materials ( $8 \mathrm{~g}$ of each of the three species) were also autoclaved. The fungus inoculum to be used had been grown for 1 month on $10 \mathrm{~g}$ of a mixture of the fragments of leaves and stems of three plant species. Then, $800 \mathrm{~g}$ shale were evenly placed in the base of the main chamber (Bed Shale), followed by $25 \mathrm{~g}$ leaves and stem pieces that were mixed with $200 \mathrm{~g}$ bentonite shale, plus $10 \mathrm{~g}$ fungal-infested plant material. The plant/shale layer was overlaid with the steel mesh envelope containing $200 \mathrm{~g}$ of baked sterile shale as the "Trap Shale". On top of the "Trap Shale" screen was scattered an additional $10 \mathrm{~g}$ fungal inoculated plant material (Fig. 3). The top plate with viewing port was sealed after 1.21 of water had been added to the main chamber (Fig. 1). The peristaltic pump was then turned on and adjusted to a $50 \mathrm{rpm}$ rate in order to circulate and move the water and fungal spores and hyphal fragments in the system. Sterile air was applied to the system. An initial 4 days of incubation and leaching of the plant materials by the water was critical to the success of the experiment since the tannins present in the plant materials prevent the abundant growth of the fungus. The Carbotrap was not connected to the exhaust of the main chamber until after this 4 day period since fungal growth was at a minimum. Then, all water that was drained from the system $(450 \mathrm{ml})$ and fresh water added from the reservoir. After 4 additional days, the system was again drained and allowed to incubate without free 


\section{Author'spersonalcopy}

Biotechnol Lett

Fig. 3 An artist's sketch of the experiment set-up of the Paleobiosphere with a bed layer overlaid with a mixture of $200 \mathrm{~g}$ of shale, $25 \mathrm{~g}$ of plant materials and $10 \mathrm{~g}$ of 1 month old plant matter infested with the fungus. The Trap Shale $(200 \mathrm{~g})$ is contained in an envelope of stainless steel overlaying the shale/plant mixture. On top is a lightly distributed fungal inoculum of infested plant material

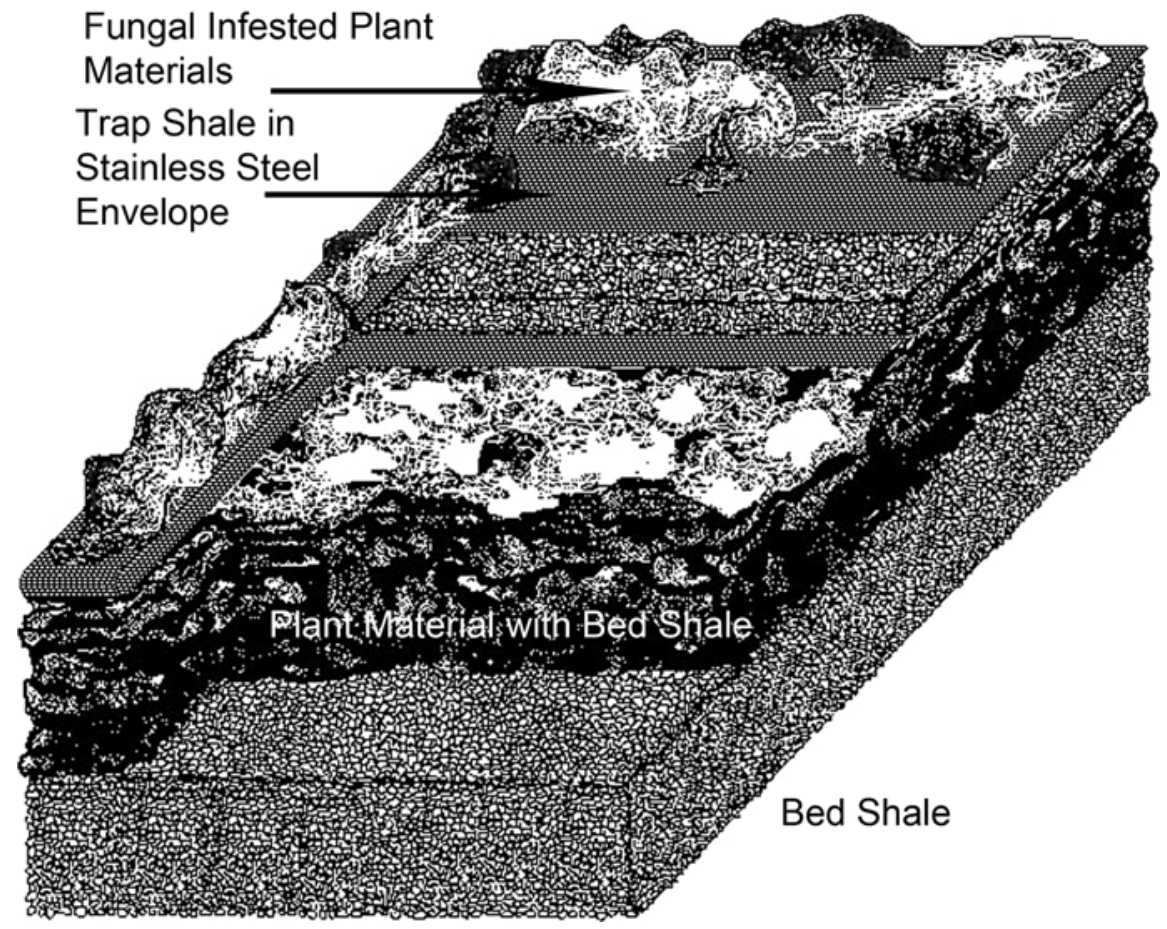

water for 4 days, at which time new water was added, the pump turned on and the process repeated twice again with a 5 day final drain period until 21 days had expired. The water cycling was done to mimic the conditions of periodic rainfall in a semi-tropical rainforest. Periodically, additional water was added to allow for an adequate flow through the system since some drying was occurring. The control PBS was treated exactly as above except no fungal inoculum was placed in the main chamber, only autoclaved leaves and stems in the same amounts. The amount of Carbotrapped hydrocarbons was determined gravimetrically after a dry purge, and then desorbed and weighed again (Booth et al. 2011). The shale harvested from the "Trap Shale" was also desorbed by heating and trapped in a vial cooled with liquid nitrogen (Booth et al. 2011). In order to achieve, what appears to be an optimum experimental outline as described above, many preliminary experiments were conducted. The results on these experiments provided guidance on what conditions would be best suited for the PBS.

The amount of Carbotrapped hydrocarbons was determined by gravimetric means, after a dry purge, and then desorbed and weighed again (Booth et al. 2011). The shale harvested from the "Trap Shale" was also desorbed by heating and trapped in a vial cooled with liquid nitrogen (Booth et al. 2011).

Results

Hydrocarbon Production by Annulohypoxylon sp.

When Annulohypoxylon sp. was grown on PDA for 10 days and assayed for the production of volatiles several hydrocarbon derivatives appeared of interest including 1,8-cineole, 1-butanol, 3-methyl- and 2-naphthalenol, 3-methyl (Table 1). These compounds served as the signature substances in the PBS and thus indicate what compounds produced therein were of fungal origin (Table 1).While the list is not long it did serve to encourage further studies on this endophytic fungus. Surprisingly, when the organism was grown in a 71 batch of PD broth with shaking and the hydrocarbons trapped on a Carbotrap column, eluted and analyzed, the number of detectable hydrocarbon-related compounds produced by this fungus greatly increased over the plate GC/MS analysis and included representative compounds in each class of crude oil substances. Present in the analysis were branched hydrocarbons, benzene derivatives, cycloalkanes, some polyaromatic hydrocarbons 
(the azulenes) and various smaller molecular weight aldehydes, esters, acids and alcohols (Table 2). Of great interest was the appearance of a number of cycloalkanes including cyclohexane, cyclohexene, cyclohexanone, and cyclopentane derivatives since many of these reduced products are some of the most abundant compounds associated with crude oils and diesel fuels. It is notable that stereo-centers exist in some of these molecules as well with comparable compounds found in diesel (Table 2). Some of the key compounds found in the PDA plate with the fungus did not appear in the Carbotrap fraction including 1,8-cineole, but others did appear and this is undoubtedly related to the conditions of fungal growth. Nevertheless, this organism was selected for use in the PBS in order to learn if its volatiles would collect in the "Trap Shale" of the instrument since the spectrum of volatiles being made were very promising.

\section{The Paleobiosphere experiment}

The plant materials selected for use in the PBS supported fungal growth very well (Fig. 4). This included leaves of three plant species selected on the basis of their paleobotanical origins (Fig. 2). Stem pieces of these species were also added to the instrument since paleobotanical evidence has been discovered showing the presence of fossilized fungi in stem tissues in Montana shale near the same location as the shale used in these experiments (Fig. 2). The
Annulohypoxylon sp. was capable of colonizing each of the plant materials in the PBS including leaf blades, petioles and stem fragments after a few days of leaching with sterile water.

In the PBS, colonization of the plant materials began in earnest after 4 days when the first free water was removed and eventually completely engulfed all biological materials (Fig. 4). Removal of free water on a periodic basis served to leach tannins from the leaves and stems in the PBS and promoted fungal growth. In natural conditions, these polyphenolic substances are inhibitory to fungi and the leaching of plant materials on the forest floor occurs during a rainfall resulting in a concomitant dark discoloration of rainforest streams and rivers. It was obvious that the control PBS was much less dark with less absorbance at $260 \mathrm{~nm}$ than the PBS supporting fungal growth both at the beginning and at the end of the incubation period (Table 1). Quite unexpectedly, the fungus had also colonized the "Trap Shale" in the PBS (Fig. 4).

Trapped hydrocarbons in the Paleobiosphere

At the termination of the experiment $29.8 \mathrm{mg}$ hydrocarbons were trapped by the "Trap Shale" in the PBS containing the fungus as compared to $1.2 \mathrm{mg}$ in the control (Table 1). Likewise, over eight times the amount of hydrocarbons on the Carbotrap in the fungal PBS than the control PBS were trapped (Table 1). About $50 \%$ of the trapped hydrocarbons were

Table 1 A GC/MS analysis of the volatiles being produced on a 10 day old culture of Annulohypoxylon sp. actively growing on a potato/dextrose/agar plate

\begin{tabular}{|c|c|c|c|c|}
\hline $\begin{array}{l}\text { Retention time } \\
(\mathrm{min})\end{array}$ & Relative area & Compound & $\begin{array}{l}\text { Molecular weight } \\
(\mathrm{g} / \mathrm{mol})\end{array}$ & Quality \\
\hline 5.15 & 51 & 1-Propene, 2-methyl-, trimer & 168 & 83 \\
\hline 5.91 & 52 & ${ }^{+}$a-Thujene & 136 & 90 \\
\hline 10.15 & 55 & +*Benzene, 1,3-dimethyl- & 106 & 97 \\
\hline 10.71 & 3332 & ${ }^{+} 1,8$-Cineole & 154 & 98 \\
\hline 10.88 & 231 & ${ }^{+}$1-Butanol, 3-methyl- & 88 & 83 \\
\hline 19.57 & 4662 & ${ }^{*+}$ Benzaldehyde & 106 & 97 \\
\hline 24.25 & 87 & ${ }^{+}$trans-Caryophyllene & 204 & 70 \\
\hline 41.8 & 455 & 2-Naphthalenol, 3-methoxy- & 174 & 90 \\
\hline- & 1508 & 7 Unknowns & - & - \\
\hline Overall area & 12513 & & & \\
\hline
\end{tabular}

The details of the analysis are in "Materials and methods"

* Sometimes found in control plates in small concentrations

+ An authentic compound yielded the same spectrum and retention time as the fungal product 
Biotechnol Lett

Table 2 A GC/MS analysis of the Carbotrapped gases of Annulohypoxylon sp. after a 2 week incubation on a 71 culture grown on potato dextrose broth at $22{ }^{\circ} \mathrm{C}$

\begin{tabular}{|c|c|c|c|c|}
\hline $\begin{array}{l}\text { Retention time } \\
(\min )\end{array}$ & $\begin{array}{l}\text { Relative } \\
\text { area }\end{array}$ & Compound & $\begin{array}{l}\text { Molecular } \\
\text { weight } \\
(\mathrm{g} / \mathrm{mol})\end{array}$ & Quality \\
\hline 1.89 & 129 & ${ }^{+}$Acetaldehyde & 44 & 74 \\
\hline 2.51 & 3887 & Cyclobutane, ethenyl- & 82 & 94 \\
\hline 3.69 & 569 & ${ }^{+}$2-Butanone & 72 & 78 \\
\hline 4.06 & 783 & ${ }^{+}$Propanoic acid, 2-methyl-, methyl ester & 102 & 91 \\
\hline 4.62 & 572 & Furan, 2,5-dimethyl- & 96 & 91 \\
\hline 6.59 & 6241 & ${ }^{+}$2-Butenal, (E)- & 70 & 91 \\
\hline 7.28 & 33 & 1-Butanol, 3-methyl-, formate & 116 & 72 \\
\hline 8.72 & 59 & Cyclohexane, 1,2,4-tris(methylene)- & 120 & 81 \\
\hline 9.04 & 33 & Cyclohexene, 1-(1-propynyl)- & 120 & 81 \\
\hline 10.02 & 21 & Benzene, (1-methylethyl)- & 120 & 91 \\
\hline 10.95 & 846 & Cyclobutanone, 2-ethyl- & 98 & 72 \\
\hline 10.96 & 71 & ${ }^{+} 1$-Butanol, 3-methyl- & 88 & 78 \\
\hline 11.45 & 27 & Dodecane, 2, 6, 11-trimethyl- (or isomer) & 212 & 80 \\
\hline 12.11 & 19 & Benzene, cyclopropyl- & 118 & 92 \\
\hline 12.71 & 35 & Benzene, 1-methyl-2-(1-methylethyl)- & 134 & 95 \\
\hline 12.97 & 16 & Dodecane, 2, 6, 11-trimethyl- & 212 & 93 \\
\hline 15.10 & 15 & Benzene, 1-ethenyl-2-methyl- & 118 & 94 \\
\hline 15.69 & 77 & 1,3-Cyclopentadiene, 5-(1-methylpropylidene)- & 120 & 80 \\
\hline 16.48 & 27 & Bicyclo[4.2.0]octa-1,3,5-triene, 7-methyl- & 118 & 95 \\
\hline 17.76 & 180 & ${ }^{+}$Acetic acid & 60 & 90 \\
\hline 18.67 & 23 & Cyclohexanone, 5-methyl-2-(1-methylethyl), cis- & 154 & 98 \\
\hline 19.06 & 15 & Longifolene-(V4) & 204 & 78 \\
\hline 19.34 & 14782 & Formic acid & 46 & 78 \\
\hline 20.07 & 2422 & ${ }^{+}$Propanoic acid & 74 & 91 \\
\hline 21.05 & 114 & Cyclohexane, 1-ethenyl-1-methyl-2,4-bis(1-methylethenyl)-, [1S-(1a,2b,4b)]- & 204 & 99 \\
\hline 23.50 & 669 & $2(5 \mathrm{H})$-Furanone, 5-methyl- & 98 & 90 \\
\hline 23.66 & 34 & Bicyclo[3.1.0]hexane, 6-isopropylidene-1-methyl- & 136 & 86 \\
\hline 24.37 & 791 & $\begin{array}{l}\text { Azulene, } 1,2,3,5,6,7,8,8 \mathrm{a}-\text { octahydro-1,4-dimethyl-7-(1-methylethenyl), } \\
\text { [1S-(1a,7a,8ab)]- }\end{array}$ & 204 & $>70$ \\
\hline 24.55 & 287 & Caryophyllene & 204 & 81 \\
\hline 25.15 & 14 & $\begin{array}{l}\text { 1H-Cycloprop[e]azulene, decahydro-1,1,7-trimethyl-4-methylene-, } \\
\text { [1aR-(1aa,4ab,7a,7ab,7ba)]- }\end{array}$ & 204 & 89 \\
\hline 25.80 & 46 & 2-Propenoic acid, 2-phenylethyl ester & 176 & 72 \\
\hline 28.48 & 8847 & ${ }^{+}$Phenylethyl alcohol & 122 & 94 \\
\hline 39.05 & 888 & Benzophenone & 182 & 96 \\
\hline- & 10245 & 29 Unknown compounds & - & - \\
\hline Overall area & 52819 & & & \\
\hline
\end{tabular}

The conditions of the experiment are in the "Materials and methods". The dry weight of the fungus was $22 \mathrm{~g}$

+ Indicates that an authentic control had the same retention and MS as the fungal product

recovered as liquids from each of the Carbotraps when desorbed and condensed in a vial in the presence of liquid nitrogen (Table 1). These results suggest that the fungus introduced into the PBS was contributing to the production of hydrocarbons in the PBS system and that the "Trap Shale" did function "in vivo" to collect 


\section{Author'spersonalcopy}

Biotechnol Lett
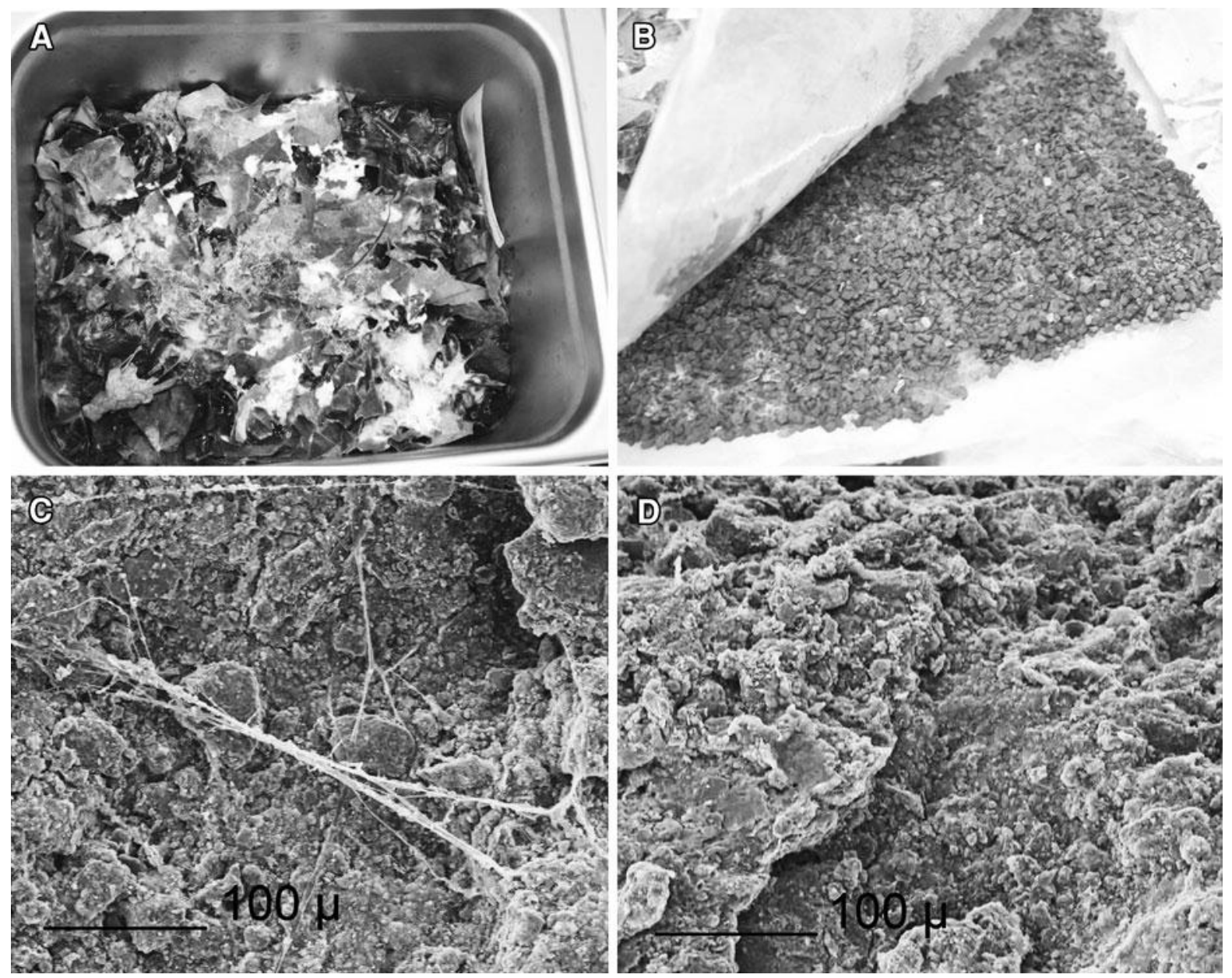

Fig. 4 Illustration a represents the PBS (under the "Trap Shale" layer) at the termination of the experiment. The leaves and shale materials are completely covered with fungal hyphae On the other hand; the "Trap Shale" itself (b) (when the stainless steel mesh screen was removed) was damp and covered

some of the hydrocarbons produced in the PBS but non-trapped ones were effectively removed from the gas stream by the Carbotrap attached to the PBS (Fig. 1; Table 1).

Nature of the trapped hydrocarbons from the PBS

Compounds recovered from the "Trap Shale" in the PBS containing the fungus include representatives of all of the major classes of compounds found in diesel including straight and branched chained hydrocarbons, cyclic alkanes, benzene derivatives and polyaromatic hydrocarbons such as the naphthalenes and azulenes. Most importantly, the major signature compounds of

with fungal hyphae. Actual width of the main chamber is $30 \mathrm{~cm}$. An SEM of fungal hyphae growing on the surface of a shale particle (c) (treatment shale) and no evidence of any hyphae on the control shale $(\mathrm{d})$

2-butanone, propanoic acid, 2-methyl-,methyl ester, benzene(1-methylethyl)-, 1,8-cineole, phenylethyl alcohol, benzophenone and azulene, 1,2,3,5,6,7,8,8 a-octahydro-1,4-dimethyl-7-(1-methylethenyl), [1S$(1 \mathrm{a}, 7 \mathrm{a}, 8 \mathrm{ab})]-$ each appeared in the "Trap Shale" (Table 4). This observation provides unequivocal evidence that fungal hydrocarbons, produced in the plant decay processes, can be trapped and retained by the bentonite shale. Even upon extensive drying ( $30 \mathrm{~h}$ at $30{ }^{\circ} \mathrm{C}$ ) the majority of these substances were retained by the shale (G Strobel unpublished work).

Other volatile compounds appearing on the "Trap Shale"-list of hydrocarbons were either made by fungal metabolism or released products from the plant 
Table 3 Collective data on the recovery of hydrocarbons from the PBS treatment (with the endophytic fungus - Annulohypoxylon sp.) and the control (without the fungus)

\begin{tabular}{llllll}
\hline & $\begin{array}{l}\text { Carbotrap total } \\
\text { hydrocarbons } \\
(\mathrm{mg})\end{array}$ & $\begin{array}{l}\text { Recovered from } \\
\text { Carbotrap (mg) }\end{array}$ & $\begin{array}{l}\text { Trap Shale recovered } \\
\text { hydrocarbons (mg) }\end{array}$ & $\begin{array}{l}\text { Total absorbance first } \\
\text { water from PBS at 260 k }\end{array}$ & $\begin{array}{l}\text { Total absorbance last } \\
\text { water from PBS at 260 k }\end{array}$ \\
\hline $\begin{array}{c}\text { PBS with } \\
\text { fungus }\end{array}$ & 67.0 & 44.6 & 29.8 & 8325 & 5875 \\
$\begin{array}{c}\text { PBS control } \\
\text { without } \\
\text { fungus }\end{array}$ & 8.0 & 3.0 & 1.2 & 4675 & 1875 \\
\hline
\end{tabular}

All methods used for the analysis are found in the "Materials and methods" section. The results in this table are from one experiment and are exemplary of other experiments that were conducted with the PBS. Obtaining identical set-ups with this particular experimental design is virtually impossible given the heterogeneous nature of the substrates and trapping materials

materials by fungal action since all compounds in the control "Trap Shale" and Carbotrap - control shale were removed from this list. It would appear, for instance that the cyclohexanes-butyl and pentyl derivatives are directly a result of fungal metabolism since cyclohexanes, cyclohexenes and cyclohexanones were all detected in the fungal hydrocarbon mixture from the Carbotrap of a 71 culture (Tables 2, 4). Furthermore, compounds of this type are not generally found in higher plants suggesting that the plant material was not the direct source of the compounds (Robinson 1983). Likewise, it appears that the fungus is capable of making a number of benzene derivatives, including the indanes and estragole, but only one appears to be common in the both the 71 liquid culture Carbotrap and "Trap Shale" samples (Tables 2, 4). Also all of the 4-5 carbon aldehydes and esters such as 2-butenal, 2-methyl are of fungal origin since relatives of these compounds are in the "Trap Shale" products, for instance 3-methyl- and 1-butanol, formate in the Carbotrap and the acetate derivative appearing in the "Trap Shale" (Tables 2, 4). Another compound of interest is 3-octanone which commonly appears in the analysis of fungal hydrocarbons and can be found in GC/MS analysis of crude oil from Melstone, Montana, crude oil (G Strobel unpublished; Table 4). This aldehyde is not found in plants (Robinson 1983). It is also noteworthy that various hydro-naphthalene derivatives are found in the analysis of the "Trap Shale" and these types of volatiles are commonly associated with diesel. Naphthalene and naphthalene derivatives are only rarely found in plants but have been found in the analysis of fungal hydrocarbons and thus are probably of fungal origin (Daisy et al. 2002; Strobel 2006). Also of interest, are the straight and branched chained hydrocarbons that appeared in the "Trap Shale" analysis (Table 4). Hydrocarbons of this type have been noted in the gas analysis of the Carbotrap contents in the 71 fermentation and have been previously reported from other fungi (Tables 2, 4; Ahamed and Ahring 2011; Banerjee et al. 2010; Griffin et al. 2010; Strobel et al. 2008). Most likely they too are of fungal origin. Finally, there is an apparent absence of any of the small molecular weight organic acids (formic, acetic and propanoic) in the Carbotrap of the 71 fermentation but not in the Trap Shale of the PBS (Tables 2,4). This suggests that the shale is somewhat selective in the types of molecules that may be trapped by it. It is obvious that the fungus makes these acidic molecules in the PBS since so many esters of these compounds were trapped by the shale (Table 4).

\section{The Carbotraps}

A relative large hydrocarbon fraction was recovered from the Carbotrap in the PBS (Table 3). These compounds had escaped being collected by the "Trap Shale" in the PBS and left the chamber of the instrument only to be trapped by the Carbotrap materials (Fig. 1; Table 3).The compounds were some of the same substances that were on the "Trap Shale" as well as numerous related straight and branched chained hydrocarbons, cycloalkanes, benzene derivatives and others (Table 4). Likewise, the amount of hydrocarbons in the Carbotrap of the control PBS was substantially lower than the fungal counterpart (Table 3). It mostly contained an assortment of aldehydes, ketones, benzenes and furans. These compounds were present in low 
Table 4 The hydrocarbon products recovered from the PBS (treated-fungal) $200 \mathrm{~g}$ of "Trap Shale" under the conditions described in the "Materials and methods" section

\begin{tabular}{|c|c|c|c|c|}
\hline $\begin{array}{l}\text { Retention time } \\
(\min )\end{array}$ & Relative area & Compound & $\begin{array}{l}\text { Molecular weight } \\
(\mathrm{g} / \mathrm{mol})\end{array}$ & Quality \\
\hline 3.46 & 713 & Ethyl acetate & 88 & 91 \\
\hline 3.67 & 388 & 2-Butanone & 72 & 72 \\
\hline 4.01 & 1747 & Propanoic acid, 2-methyl-, methyl ester & 102 & 91 \\
\hline 5.82 & 184 & Acetic acid, 2-methylpropyl ester & 116 & 78 \\
\hline 5.96 & 485 & Decane, 4-ethyl- & 170 & 80 \\
\hline 7.13 & 430 & Cyclohexane, butyl- & 140 & 72 \\
\hline 7.43 & 634 & Undecane & 156 & 97 \\
\hline 7.88 & 118 & 2-Butenal, 2-methyl-, (E)- & 84 & 94 \\
\hline 8.46 & 2255 & 1-Butanol, 3-methyl-, acetate & 130 & 80 \\
\hline 9.07 & 789 & Naphthalene, decahydro-, trans- & 138 & 92 \\
\hline 9.73 & 413 & Cyclohexane, pentyl- & 154 & 87 \\
\hline 9.74 & 78 & 1-Penten-3-ol & 86 & 72 \\
\hline 9.87 & 75 & Benzene (1-methylethyl)- & 120 & $>70$ \\
\hline 10.05 & 616 & Dodecane & 170 & 87 \\
\hline 10.21 & 665 & trans-Decalin, 2-methyl- & 152 & 93 \\
\hline 10.79 & 207 & 1,8 Cineole & 154 & $>70$ \\
\hline 11.02 & 402 & trans-4a-Methyl-decahydronaphthalene & 152 & 86 \\
\hline 12.20 & 488 & 3-Octanone & 128 & 94 \\
\hline 13.55 & 400 & Benzene, 1-methyl-4-propyl- & 134 & 91 \\
\hline 13.98 & 427 & Butanoic acid, 3-hexenyl ester, (Z)- & 170 & 72 \\
\hline 15.13 & 447 & Benzene, 1-ethyl-2, 4-dimethyl- & 134 & 95 \\
\hline 15.49 & 420 & Indane & 118 & 76 \\
\hline 16.17 & 419 & Indane, 1-methyl- & 132 & 87 \\
\hline 16.32 & 382 & 4-Hepten-3-one, 5-ethyl-4-methyl- & 154 & 76 \\
\hline 18.25 & 775 & $\begin{array}{l}\text { 4,7-Methanoazulene, 1,2,3,4,5,6,7,8-octahydro-1,4,9, } \\
\text { 9-tetramethyl-, [1S-(1a,4a,7a)]- }\end{array}$ & 204 & 98 \\
\hline 18.59 & 628 & Benzene, 1,2,3,5-tetramethyl- & 134 & 94 \\
\hline 18.92 & 561 & Benzene, 1-ethenyl-4-ethyl- & 132 & 87 \\
\hline 19.01 & 531 & Benzene, (1-methyl-1-butenyl)- & 146 & 91 \\
\hline 19.02 & 553 & 1H-Indene, 2,3-dihydro-1,2-dimethyl- & 146 & 76 \\
\hline 19.58 & 479 & Naphthalene, 1,2,3,4,-tetrahydro- & 132 & 86 \\
\hline 20.46 & 483 & Benzene, pentamethyl- & 148 & 93 \\
\hline 22.06 & 466 & Benzaldehyde, 3-methyl- & 120 & 97 \\
\hline 23.08 & 371 & Estragole & 148 & 98 \\
\hline 23.98 & 2656 & $\begin{array}{l}\text { Azulene, } 1,2,3,5,6,7,8,8 \mathrm{a}-\text { octahydro-1,4-dimethyl-7- } \\
\text { (1-methylethenyl), [1S-(1a,7a,8ab)]- }\end{array}$ & 204 & 99 \\
\hline 24.33 & 70 & Benzene, 1,2-dimethoxy- & 138 & 97 \\
\hline 28.47 & 68 & Phenylethyl alcohol & 122 & 94 \\
\hline 39.04 & 60 & Benzophenone & 182 & 91 \\
\hline- & 11420 & 18 Unknown compounds & - & - \\
\hline Overall area & 32740 & & & \\
\hline
\end{tabular}

Compounds that are in bold letters are those also found in the Carbotrap of the 71 culture of Annulohypoxylon sp. in Table 2. All compounds found in the control "Trap Shale" and Carbotrap have been subtracted from this list 
amounts in the control Carotrap and only a few were the same as those in the fungal PBS-Carbotrap. The source of these volatiles in the Control Carbotrap is undoubtedly related to the autoclaving of the plant materials and changes brought by heating and wetting of the materials.

\section{Conclusions}

The main thrust of this report is to show the development and testing of a device termed the Paleobiosphere. This device was constructed to mimic some of the conditions of the ancient earth in order to provide evidence for the hypothesis that the biological degradation (using an endophytic fungus) of plant materials can be an apparent source of hydrocarbons using shale as a trapping medium for the microbial derived compounds. Overall, it appears that the initial experiments to demonstrate this phenomenon have provided some experimental evidence for the hypothesis (Tables 3, 4). Of course, not all hydrocarbonbased compounds currently found in crude oil or in diesel were present in the final "Trap Shale" analysis of the PBS but representative compounds in each class of substance in diesel were present (Table 4). This finding, at least provides a basis for further studies using the PBS in a multitude of different ways. These may include modifications of substrata, individual microbes and combinations thereof as well as the trapping media (other shales, sands and limestones) as well as variations of temperature, water levels and length of incubation periods. One obvious test is an experimental set up in which nothing is sterilized and only the natural flora of both the shale and the nonautoclaved plant materials are added to the PBS.

It seems likely that the processes involving hydrocarbon formation in the earth did not take millions of years and tons of pressure and high temperatures as proposed. It does appear likely that some plantassociated microorganisms were involved in producing some of the ingredients in crude oil as well as sets of other slightly oxygenated molecules that were the precursors of totally reduced hydrocarbons (as found in crude oil). Presently, it seems impossible to determine which extant microbes are identical or related to the ancient microbes that may have carried out these processes, but we know that they were present and maybe they possessed different biochemical capabilities than extant microbes (Fig. 2). In addition, some of these biologically-produced molecules, such as aldehydes, ketones, alcohols and alkenes released by microbes and trapped on shale under the reducing conditions of the earth, may have been modified to the final reduced products that are found in crude oil. They accumulated in shale and eventually with changing pressures in the earth's layers began to pool in certain locations. The PBS now provides unequivocal evidence of the ability of bentonite shale, in vivo, to trap hydrocarbons being produced by an endophytic fungus that is actively degrading dead plant materials.

Acknowledgments The authors acknowledge the support of the National Science Foundation (NSF) Emerging Frontiers in Research and Innovation (EFRI), Grant No. 0937613 to Dr. Brent Peyton and Chemical, Bioengineering, Environmental and Transport Systems (CBET) at MSU. The work was also supported by a Grant to GAS from the Sandia/DoE. The authors appreciate the efforts of Mr. Mark Raymond for his help with this work and in providing the drawing in Fig. 3. Finally, Mr. Joe Ahrens of Global Research and Discovery, Florida, provided a series of Florida-based plants for endophyte isolation.

\section{References}

Ahamed A, Ahring BK (2011) Production of hydrocarbon compounds by endophytic fungi Gliocaldium sp. grown on cellulose. Bioresour Technol 102:9718-9722

Bacon CW, White JF (2000) Microbial endophytes. Marcel Dekker, NewYork

Banerjee D, Strobel GA, Booth E, Geary B, Sears J, Spakowicz D, Busse S (2010) An endophytic Myrothecium inundatum producing volatile organic compounds. Mycosphere 3:241-247

Booth E, Strobel G, Knighton B, Sears J, Geary B, Avci R (2011) A rapid column technique for trapping and collecting volatile fungal hydrocarbons. Biotechnol Lett 10:1963-1972

Daisy BH, Strobel GA, Castillo U, Sears J, Weaver DK, Runyon JB (2002) Naphthalene production by Muscodor vitigenus, a novel endophytic fungus. Microbiology 148:3737-3741

Ezra D, Hess WM, Strobel GA (2004) Unique wild type endophytic isolates of Muscodor albus, a volatile antibiotic producing fungus. Microbiology 150:4023-4031

Finn TM, Kirschbaum MA, Roberts SB, Condon SM, Roberts L, Johnson RC (2010) Cretaceous-Tertiary Composite Total Petroleum System (503402), Bighorn Basin, Wyoming and Montana in Chapter 3 of Petroleum Systems and Geologic Assessment of Oil and Gas in the Bighorn Basin Province, Wyoming and Montana By US Geological Survey Bighorn Basin Province Assessment Team U. US Geological Survey Digital Data Series DDS-69-V 2010

Gianoulis TA, Griffen MA, Spakaowicz DJ, Dunican B, Alpha CJ, Sboner A, Sismour M, Kodira C, Egholm M, Church G, Gerstein MB, Strobel S (2012) Genomic analysis of the hydrocarbon-producing, cellulolytic, endophytic fungus Ascocoryne sarcoides. PLoS Genet 8(3):e1002558. doi: 10.1371/journal.pgen. 1002558 
Griffin MA, Spakowicz DJ, Gianoulis TA, Strobel SA (2010) Volatile organic compound production by organisms in the genus Ascocoryne and a re-evaluation of myco-diesel production. by NRRL 50072. Microbiology 156:3814-3829

Hassan SRU, Strobel GA, Booth E, Knighton B, Floerchinger C, Sears J (2012) Modulation of volatile organic compound formation in the mycodiesel producing endophyte- Hypoxylon sp C1-4. Microbiology 158:465-473

Heck TJ, LeFever RD, Fischer DW (2012) Overview of the petroleum geology of the North Dakota Williston Basin. North Dakota Geological Survey, North Dakota

Mallette N, Knighton WB, Strobel GA, Carlson RP, Peyton BM (2012) Resolution of volatile compound profiles from Ascocoryne sarcoides: a comparison by proton transfer reaction and gas chromatography-mass spectrometry. AMB Express (in press)

Mends MT, Yu E, Strobel GA, Hassan SRU, Booth E, Geary B, Sears J, Taatjes CA, Hadi M (2012) An endophytic Nodulisporium sp. producing volatile organic compounds having bioactivity and fuel potential. J Petroleum Environ Biotech http://dx.doi.org/10.4172/2157-7463.1000117
Robinson T (1983) The organic constituents of higher edn. Cordus Press, Amherst

Song C, Hsu C, Mochida I (2000) Chemistry of diesel fuels. Taylor and Francis, NewYork

Strobel G (2006) Muscodor albus and its biological promise. J Ind Microbiol Biotechnol 33:514-522

Strobel GA, Daisy B (2003) Bioprospecting for microbial endophytes and their natural products. Microbiol Mol Biol Rev 67:491-502

Strobel GA, Knighton B, Kluck K, Ren Y, Livinghouse T, Griffen M, Spakowicz D, Sears J (2008) The production of myco-diesel hydrocarbons and their derivatives by the endophytic fungus Gliocladium roseum (NRRL 50072). Microbiology 154:3319-3328

Tidwell W (1998) Common fossil plants of Western North America. Smithsonian Institution, Washington

Tomsheck A, Strobel GA, Booth E, Geary B, Spakowicz D, Knighton B, Floerchinger C, Sears J (2010) Hypoxylon sp an endophyte of Persea indica producing 1,8-cineole and other bioactive volatile with fuel potential. Microb Ecol 60:903-914 